\title{
IRONMAKING INCREASE OF THE SINTER BASICITY THROUGH THE INSERTION OF PARTIALLY INERT MAGNESIUM SILICATE MINI LUMPS WITH MINERALOGICALLY STABLE INTERPHASES*
}

\author{
Javier Martinez Rubio ${ }^{1}$ \\ Esteban Ruisanchez Rodriguez ${ }^{2}$
}

\begin{abstract}
In this paper we will discuss the benefits of a very innovative way of introducing $\mathrm{MgO}$ in the blast furnace operation through the sinter, using mini lumps of dunite. By changing the traditional way of using an $\mathrm{MgO}$ bearing material in fines form (particle smaller than $5 \mathrm{~mm}$ ), most of the $\mathrm{MgO}$ inserted material behaves as inert during the sintering process, with the effect of having the following parameters (among others) improved: productivity at the sintering bed, permeability inside the blast furnace, energy consumption, stability of the operation.

Keywords: Sinter; Dunite; Mini lump; Innovative.
\end{abstract}

1 Mining Engineer, General Manager, Management Department, Pasek Minerales SAU, Cariño, La Coruña, Spain.

2 Mining Engineer, Business Development Manager, Commercial Department, Pasek Minerales SAU, Cariño, La Coruña, Spain. 


\section{INTRODUCTION}

Dunite is a plutonic rock, whose main component is Olivine which has been naturally weathered over a long period of time; the rock has been extracted and processed since 1972 from the largest magnesium silicate ore mine in Spain and one of the largest in the world, located at the Spanish region of Galicia.

The mine (Figure 1) has a capacity of over one Mton per year; up to date, more than 27 Mton have been extracted, processed and commercialized.

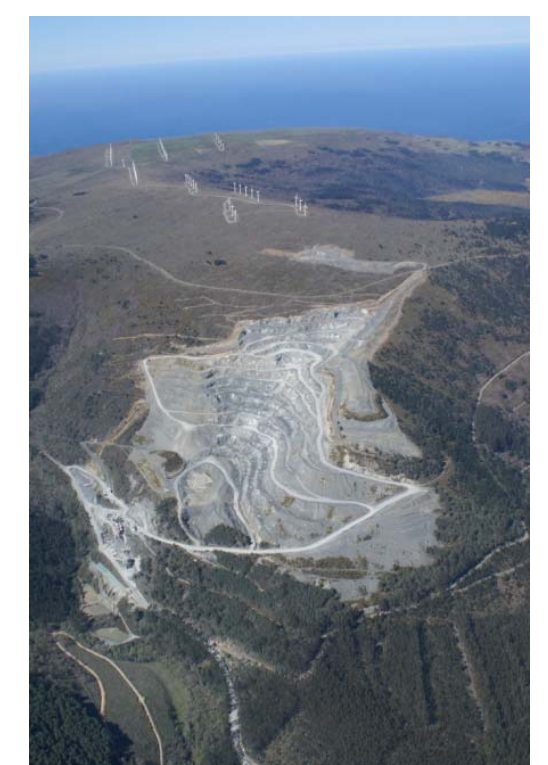

Figure 1. Spanish dunite mine in Galicia.

The benefits of using PASEK Dunite in the blast furnace are well known, as the product is being currently used all over Europe.

Due to internal logistical constraints, some plants which are interested in the use of Dunite lumps do not have the required structure for it (additional silos, conveyor belts) and have been searching for alternatives in order to be able to use the product. This paper describes a very innovative way of introducing small sized lumps of Dunite through the sinter bed, avoiding the necessity of implementing expensive logistical solutions.

\section{PASEK DUNITE}

\subsection{Physical Description}

Table 1 describes the main physical properties of Dunite. 
Table 1.

\begin{tabular}{|c|c|}
\hline Characteristic & Value \\
\hline Crushing resistence (Baron) & $1400 \mathrm{gr} / \mathrm{cm}^{2}$ \\
\hline Abrasion index (Baron) & 4.5 \\
\hline Impact resistence (IRSID) in fines & $<10 \mathrm{~mm}=6 \%$ \\
\hline Abrasion resistence (MICUM) $200 \mathrm{~T}$. in fines & $<10 \mathrm{~mm}=16 \%$ \\
\hline Thermal shock resistence $200 \mathrm{~T}$. in fines & $<10 \mathrm{~mm}=5.3 \%$ \\
\hline Hardness (MOHS scale) & $6.5-7$ \\
\hline Softening point & 1280 으 \\
\hline Fusion point & $1430 \stackrel{\circ}{C}$ \\
\hline Real density & 2.50 \\
\hline Aparent density & 1.70 \\
\hline Open porosity at $850 \stackrel{\circ}{ }$ & $19.5 \%$ \\
\hline
\end{tabular}

There are two parameters which are to be highlighted about dunite: the softening temperature $\left(1.280^{\circ} \mathrm{C}\right)$ and the open porosity above $850^{\circ} \mathrm{C}$. These are actually key factors which explain the high reactivity of the rock at industrial processes.

\subsection{Chemical description}

Dunite is a rock mainly formed by magnesium silicate compounds, whose principal basic components are oxides, such as $\mathrm{MgO}, \mathrm{SiO} 2, \mathrm{Fe} 2 \mathrm{O} 3, \mathrm{Al} 2 \mathrm{O} 3 \ldots$

Table 2 shows a detailed composition break-up of Dunite.

Table 2.

\begin{tabular}{|c|c|c|c|c|c|c|c|c|}
\hline \multirow{2}{*}{ Dunite } & \multicolumn{8}{|c|}{ Chemical Analysis } \\
\hline & MgO & $\mathrm{SiO}_{2}$ & $\mathrm{Fe} 2 \mathrm{O3}$ & $\mathrm{Al}_{2} \mathrm{O}_{3}$ & $\mathrm{CaO}$ & $\mathrm{Na}_{2} \mathrm{O}$ & $\mathrm{K}_{2} \mathrm{O}$ & LOI \\
\hline Average & 37.19 & 40.98 & 8.72 & 2.50 & 1.92 & 0.12 & 0.15 & 8.19 \\
\hline Std. Dev & 0.05 & 0.33 & 0.17 & 0.18 & 0.26 & 0.02 & 0.01 & 0.99 \\
\hline
\end{tabular}

\section{THE MINI-LUMPS CONCEPT}

\subsection{From Dunite Lumps}

There are several benefits brought into the pig iron manufacturing process by using the rock Dunite in lumpy form as a fluxing agent and slag conditioner.

All of them derive from its favorable and well-balanced physical and chemical properties, which do affect parameters of such importance for the pig iron operation like permeability in the blast furnace, effective alkalis removal and low energy consumption.

From the physical point of view (see $2-I I)$, there are three main characteristics of the rock which are to be highlighted:

- $\quad$ Low softening and melting points (1.200 and $1.430^{\circ} \mathrm{C}$, respectively).

- Very high strength to mechanical stresses (abrasion, shatter, impact...).

- Optimal grain size distribution: over $90 \%$ of the material in the range from 10 to $40 \mathrm{~mm}$. 
Regarding the chemical composition $(2-\mathrm{I})$, its LOI content derives in an important increase on the specific surface of the rock. In fact, at the moderate temperature of $800^{\circ} \mathrm{C}$, an open porosity of $20 \%$ is reached (see Figure 1 ).

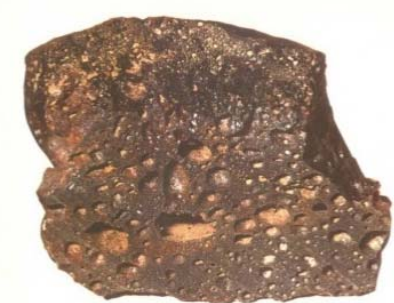

Figure 1. Calcined Dunite open porosity.

In this context, as opposed to other slag conditioners used in the industry, the fluxing activity of Dunite starts at the beginning of the operation, right after it enters the blast furnace. An analysis carried out by the Belgian Ceramic Institute (see Annex) digs into this effect (see Figure 2, where the fluxing activity of Dunite and of alternative products is represented by the white arrow).

This is actually the main reason why Dunite has been used as a fluxing agent for the last over forty years, competing in the market with other products which a higher $\mathrm{MgO}$ content but whose fluxing activity is much more limited, due to higher softening / melting temperatures and much more limited specific surface.

A comparison of the mechanisms of evacuation of alkalis by Dunite and by other alternative products may be observed on Annex 1.

\subsection{To Dunite Mini-Lumps}

It is well known that there is a global tendency since 2008 leading to an increase in the silica content of commercial iron ore.

Best quality ores with higher $\mathrm{Fe}$ content are becoming scarce and the ones coming from South America, Australia, Africa... have increasing amounts of $\mathrm{SiO} 2$ contents. This tendency is not believed to be reversed and will continue in the future.

In this context, many integrated plants are trying to:

- Optimize sinter productivity by maximizing the total Fe input through the sinter.

- Avoid the introduction of additional SiO2 into the sinter.

- Increase sinter basicity as much as the operation allows it.

This leads to a tendency of integrated plants to avoid as many raw materials outside iron ore and coke in the sinter bed as possible. In the case of Dunite, this is actually not a problem, quite the contrary, due to the benefits mentioned on $3-$ I of Dunite in the blast furnace operation: the rock is therefore most times inserted in the operation directly in lumps form.

But in some cases, certain plants face internal logistic constraints, due to lack of available raw materials bunkers, conveyor belts, etc. and have looked for alternatives to profit from the benefit of using the lumpy form of Dunite.

Late in 2011 one of the largest steel producers worldwide came up with a very innovative idea of introducing $\mathrm{MgO}$ in lump form in the process while overcoming internal logistical constraints and without the need of carrying out a significant investment. 
The innovation was to evaluate the introduction of several $\mathrm{MgO}$ bearing materials in lumpy form through the sinter bed (see Figure 3). The grain size of such lumps certainly needs to be small enough to be compatible with the sinter raw materials and smaller in any case than if introduced directly into the blast furnace (the maximum particle size the sinter mix is in the range of $10 \mathrm{~mm}$ ).

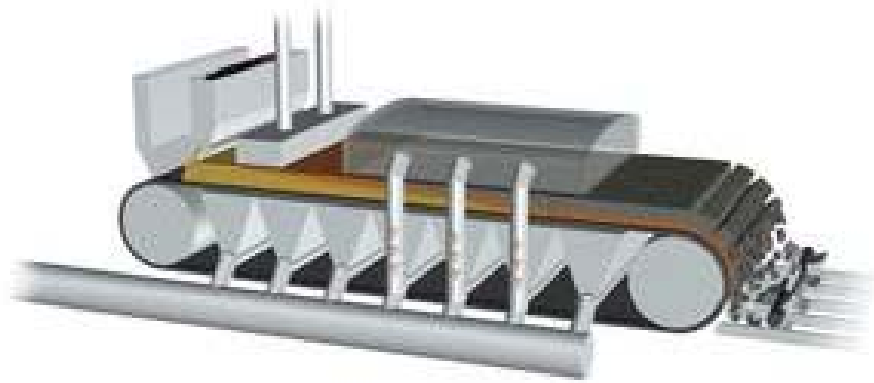

Figure 3. Sinter bed.

Following this, several tests were carried out with different types of materials, including Dunite and olivine, with different grain size distributions.

Some conclusions of these tests are the following:

\subsubsection{Interphase MgO bearing material - sínter}

At normal sinter operating temperature, Dunite finds itself at an intermediate stage, just between its softening and melting points, and reacts partially with sinter, starting from the outside layer and progressing towards the core of the rock.

As a result, at the end of the sintering process, when sinter is broken into smaller pieces which will head by conveyor belt into the blast furnace, Dunite rocks are already "glued" and evenly distributed into the sinter pieces, while most olivine stones will just fall apart and be re-screened together with the sinter fines.

Figure 4 shows a micrography of a sinter piece (dark grey color) containing a Dunite mini lump (light frey color). The interphase Dunite - sinter may be observed (medium grey color). Such interphase is in fact the mechanism through which the Dunite mini lump remains stuck to the sinter matrix at the end of the sintering process.

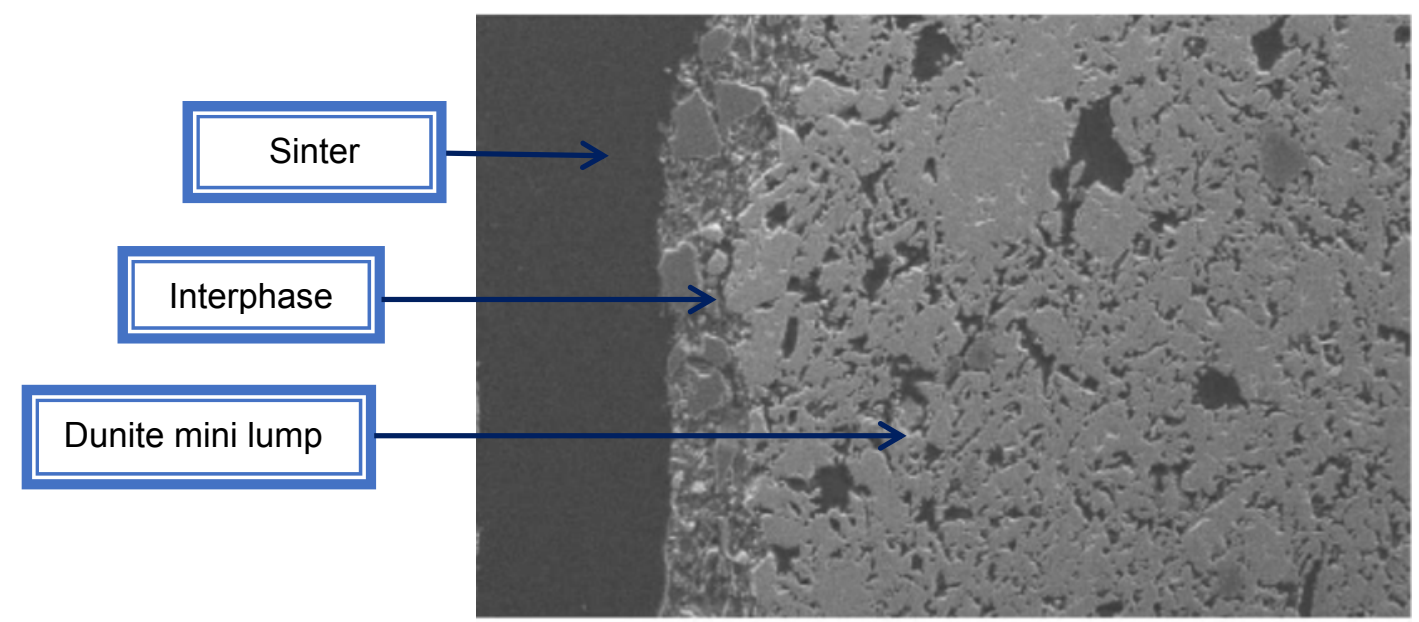

Figure 4. Micrography of sinter, Dunite mini lump and interphase between both. 
On the contrary, olivine is in a raw state at this temperature and behaves like a fully inert rock placed on top of the matrix. As a result, the interphase olivine - sinter does almost not exist and the "gluing effect" is therefore much more limited.

\subsubsection{Mini lumps optimal size}

Several tests were carried out with different grain size distributions:

1 - In the first test a $5 / 15 \mathrm{~mm}$ grain size distribution was used; the result was not satisfactory, as the standard deviation of $\mathrm{MgO}$ in the bedding pile was higher than admissible, due to the segregation of the larger particle size to the bottom of the pile. 2 - A second test was then performed with a $3 / 10 \mathrm{~mm}$. The results were much better than in the first case, as the segregation effect disappeared and the $\mathrm{MgO}$ was homogenously distributed along the pile and the sinter. A variety of this trial was conducted using $1 / 10 \mathrm{~mm}$ instead of $3 / 10 \mathrm{~mm}$. No significant change was noticed between the two options, only a slight higher degree of reacted Dunite in the sinter bed.

3 - A final test was then carried out with a $0 / 10 \mathrm{~mm}$ Dunite. The idea behind it was to analyze the effect of both products, Dunite fines $(0 / 3 \mathrm{~mm})$ and Dunite lumps $(3 / 10$ $\mathrm{mm}$ ) in operation. The results here were also satisfactory and the segregation effect was also not noticeable in this trial.

In all of the above cases, an important additional effect regarding the use of Dunite was noticed: the non-generation of any type of dust when handling the product or using it in the application, as opposed to other raw materials which were trialed. This effect does bring several benefits to the operation, both from the operational point of view as well as from environmental issues.

\subsubsection{Effects on the sinter basicity}

A new concept was introduced: the so-called "fake basicity". The idea is the possibility of increasing the basicity (the fake basicity) of the sinter by bringing inert components into the blast furnace through the sinter, without affecting its productivity. We can see this effect with the following example, with real operational figures:

1 - Let us consider a sinter bed with a normal operation (a basicity of 2 is used in this example).

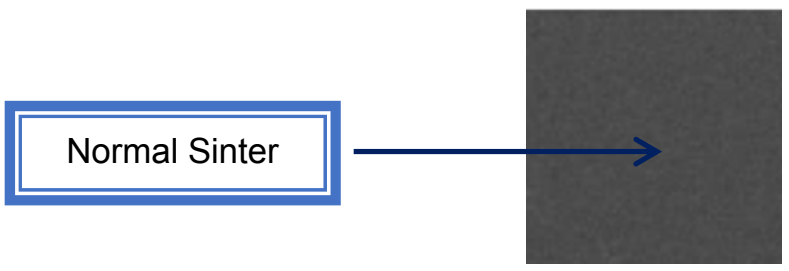

\begin{tabular}{ll}
\hline & $\begin{array}{l}\text { Normal } \\
\text { Operation }\end{array}$ \\
\hline MgO & $1 \%$ \\
$\mathrm{SiO}_{2}$ & $5 \%$ \\
$\mathrm{CaO}$ & $10 \%$ \\
Basicity & $\mathbf{2}$ \\
\hline
\end{tabular}

2 - During the trial with mini lumps it was observed that some of the $\mathrm{MgO}$ and $\mathrm{SiO} 2$ remains inert (corresponding to the Dunite mini lump which has not reacted): 


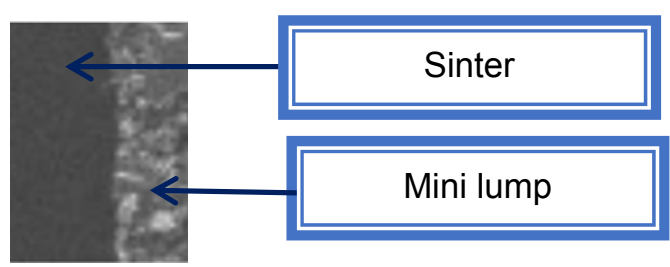

\begin{tabular}{l|l}
\hline & $\begin{array}{l}\text { Mini lumps } \\
\text { operation }\end{array}$ \\
\hline $\mathrm{MgO}$ & $0.5 \%$ \\
$\mathrm{SiO}_{2}$ & $4 \%$ \\
$\mathrm{CaO}$ & $10 \%$ \\
Basicity & $\mathbf{2 . 5}$ \\
\hline
\end{tabular}

As a result, the basicity of the sinter increases in 0.5 while the productivity and quality on the sinter bed remains.

\section{CONCLUSION}

The use of mini lumps is a very innovative method that the most important integrated plants are adopting in order to introduce $\mathrm{MgO}$ in their process in the most effective way.

Dunite shows the best balance between mechanical and physical properties for this application, as it effectively sticks to the sinter matrix and have a significant percentage of inert material which does not affect the sinter composition and reaches the blast furnace as a lump.

Plants which desire the most effective homogenization of $\mathrm{MgO}$ along the sinter bed should chose the $3 / 10$ or $1 / 10 \mathrm{~mm}$ distributions, whereas plants which need to combine both fines and lumps during agglomeration should rather use the $0 / 10 \mathrm{~mm}$ distribution.

In some of the cases a small increase of the slag level was observed (between 1 and $2 \mathrm{Kg} /$ ton of pig iron). In any case, the benefits of the introduction of the lumpy product through the sinter overcame this

The environmental evaluation of the test with Dunite was also successful, as no dust emissions were observed, no matter which grain size distribution was used for the test. 
Annex 1

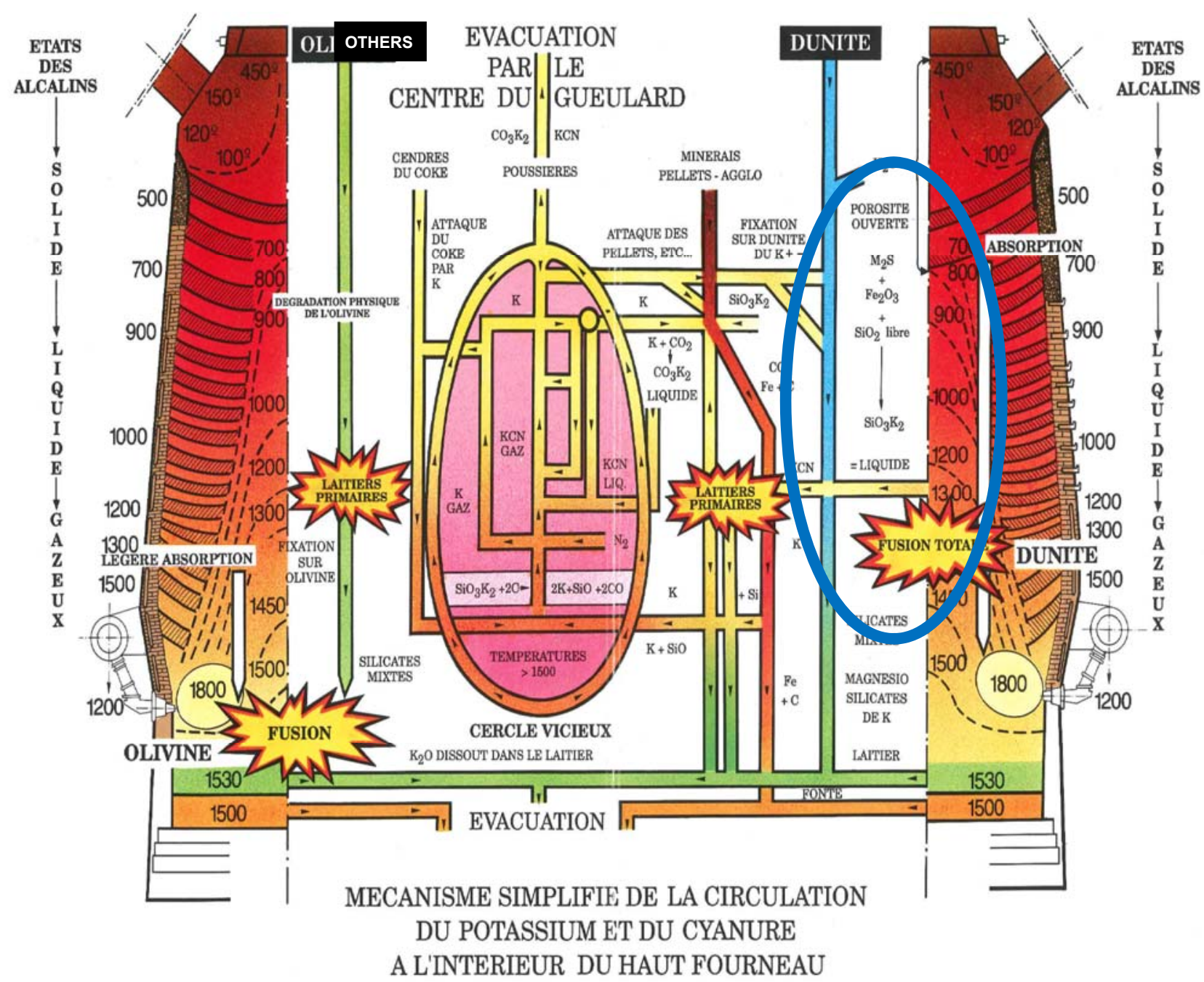

Figure 2. Alkalis evacuation mechanism Dunite vs alternative products.

\section{BIBLIOGRAPHY}

1 Tirlocq J. Etude Comparative de deux Silicates de Magnesium, en tant qu' gents d'elimination du posasium en Haut Fourneau; 2009.

2 Verbenne R, Arango PC, Caballero R. Benefits of Dunite as MgO addiction for Sinter and blast Furnace; 2010. 